\title{
Successful Use of Electroejaculation in Two Multiple Sclerosis Patients Including Report of a Pregnancy Utilizing Intrauterine Insemination
}

\author{
Dana A. Ohl, Ronald Grainger, Carol J. Bennett, John F. Randolph, \\ Stephen W.J. Seager, and Marcianna McCabe
}

Department of Surgery, Section of Urology (D.A.O., R.G., C.J.B., S.W.J.S., M.M.), and Department of Obstetrics \& Gynecology, Division of Reproductive Endocrinology and Infertility (J.F.R.), University of Michigan, Ann Arbor

\begin{abstract}
We report two males with multiple sclerosis who were infertile as a result of failure to ejaculate. Electroejaculation was successfully used to recover semen with motile sperm from both men, and the sperm was used for artificial insemination. One pregnancy was achieved by intrauterine insemination, and a healthy male baby was born.
\end{abstract}

Key words: anejaculation, artificial insemination, infertility

\section{INTRODUCTION}

Sexual dysfunction in males with multiple sclerosis is well described [Cartlidge, 1972]. Impotence is the most common problem, but failure to ejaculate may also occur. Those who are impotent may be treated with penile prosthesis implantation or intracavernous injection therapy. Those with anejaculation, however, are infertile; and until recently, no therapy was available for this condition.

\section{PATIENTS AND METHODS}

\section{Case Number 1}

In 1975, a 28-year-old man was diagnosed as having multiple sclerosis. Since then, his disease has been manifested by left leg weakness, waxing and waning weakness in the other extremities, and urinary retention. He has been impotent and

Received for publication November 10, 1988; accepted December 9, 1988.

Dr. Bennett is now at Department of Urology, University of Southern California, Los Angeles, CA.

This work was supported by a grant from the Eastern Paralyzed Veterans of America.

Address reprint requests to Dana A. Ohl, M.D., 1500 E. Medical Center Drive, 2916 Taubman Center, Box 0330, Ann Arbor, MI 48109.

(C) 1989 Alan R. Liss, Inc. 
anejaculatory since 1976 . Erections are achieved at present by papavarine injections. A trial of ephedine to restore ejaculation was unsuccessful and examination of a postmasturbation urine showed no evidence of sperm.

He presented for electroejaculation in 1988 at the age of 41 years. The procedure was attempted without anesthesia, but could not be completed because of pain. Electroejaculation was subsequently carried out on two consecutive days (coinciding with the wife's ovulation) under general anesthesia and antegrade and retrograde ejaculate containing motile sperm was obtained on each day. Sperm washing and swim-up was carried out to prepare samples used for intrauterine insemination. The processed samples (after swim-up) yielded 48 million sperm with $15 \%$ motility and 9 million sperm with $20 \%$ motility on the 1 st and 2 nd days, respectively. The patient's wife did not conceive. Further insemination trials are planned for this couple.

\section{Case Number 2}

In 1980 a 25-year-old man was first diagnosed as having multiple sclerosis. Initial presenting symptoms included pain along the left side of his body and transient urinary and fecal incontinence. Neurological signs at that time included bilateral ankle clonus and a positive left Babinski reflex. Four months after the diagnosis of multiple sclerosis, the patient became anejaculatory. He was married 9 months following diagnosis. Normal erectile function was maintained and coitus occurred on an average of three times per week. Postcoital urine was examined on several occasions for sperm but was negative on each occasion. Treatment with phenylpropanolamine was unsuccessful in restoring ejaculation.

By 1985 urological symptoms of hesitancy and poor stream had developed. A urodynamics study performed at this time demonstrated uninhibited bladder activity with detrusor-sphincter dyssynergia (DSD), and a program of clean intermittent self-catheterization and anticholinergic medication was begun. The course of his MS has been one of intermittent relapses and acute exacerbations, which are responsive to treatment with dexamethasone.

The patient was first seen in August 1985 at the age of 30 for consideration for electroejaculation, and from August 1985 through July 1986, he underwent a total of 14 trials. These procedures were performed with IV sedation using a combination of meperidine and a benzodiazepine. Total sperm counts (combination of antegrade and retrograde specimens) ranged from 3.6 to $67 \times 10^{6}$, sperm motility varied from $10 \%$ to $70 \%$, and there were $30 \%$ to $70 \%$ normal morphological forms. Multiple vaginal artificial inseminations were carried out with nonprocessed semen but were unsuccessful in achieving a pregnancy.

After a period of 16 months the patient again presented for further electroejaculation trials. The first electroejaculation on return visit was successful in obtaining motile sperm in both antegrade and retrograde ejaculate. The subsequent trial was timed with the spouse's ovulation and intrauterine insemination was performed. The processed (swim-up) sample contained $20 \times 10^{6}$ spermatozoa with $65 \%$ motility. The spouse became pregnant, and an ultrasound showed a single intrauterine pregnancy (Fig. 1). 


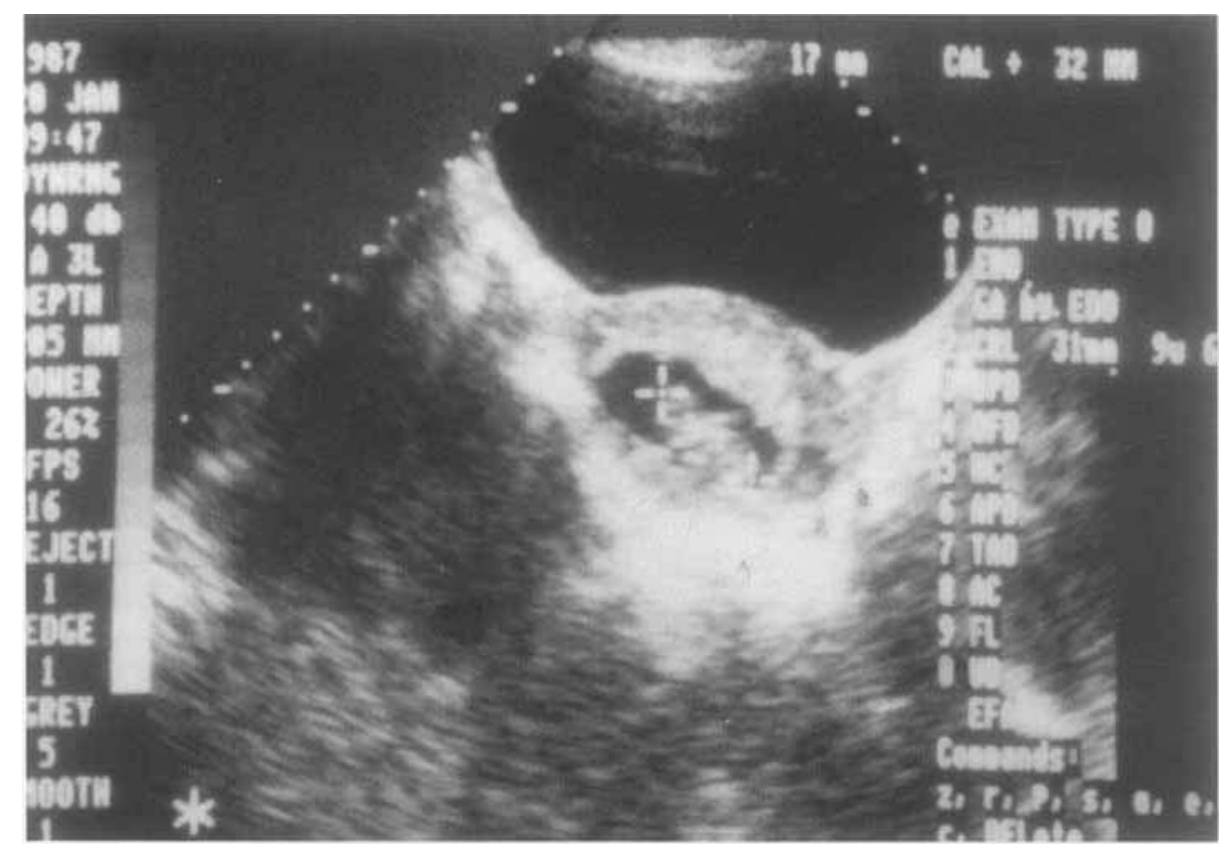

Fig. 1. Abdominal ultrasound showing single intrauterine pregnancy in spouse of patient 2 .

\section{DISCUSSION}

Sexual dysfunction in males with multiple sclerosis usually presents as erectile impotence and loss of libido. Isolated absence of ejaculation occurs less frequently. Our second patient, however, had normal erections and libido but complete absence of antegrade or retrograde ejaculation.

Electroejaculation is a well-recognized technique, which has been used for inducing emission of semen both in animals [Seager et al., 1980] and in humans [Brindley, 1980; Martin et al., 1983]. Our technique employs an electrical probe which is placed in the rectum. The probe is connected to an electrical stimulator and temperature meter and the current is delivered in a sine-wave pattern. During stimulation, the bipolar electrodes are directed anteriorly to stimulate the short neurons entering the ejaculatory organs, which lie anterior to the rectum. As the electrical stimulus is being applied, the bulbous and pendulous urethra are "milked" to encourage an antegrade ejaculate. The patient is catheterized after cessation of electrical stimulation to recover any retrograde ejaculate. The bladder is irrigated with modified Hamm's F-10 solution to retrieve the maximum number of sperm. Hitherto, the most widely used successful application of electroejaculation has been in spinal-cord-injury patients [Thomas et al., 1975; Bennett et al., 1988; Ohl et al., 1988]. It has also been used to obtain semen after retroperitoneal lymph node dissection [Bennett et al., 1987]. 
These are the first reported cases of the successful use of electroejaculation in multiple sclerosis patients with ejaculatory failure. As in the case of spinal cord injury and retroperitoneal lymph node dissection, we believe that electroejaculation offers hope to men with multiple sclerosis who, despite sexual dysfunction, may wish to father children.

\section{REFERENCES}

Bennett CJ, Seager SW, McGuire EJ (1987): Electroejaculation for recovery of semen after retroperitoneal lymph node dissection: Case report. J Urol 137:513-515.

Bennett CJ, Seager SW, Vasher E, McGuire EJ (1988): Sexual dysfunction and electroejaculation in men with spinal cord injury: Review. J Urol 139:453-457.

Brindley GS (1981): Electroejaculation: Its technique, neurological implications and uses. J Neurol Neurosurg Psychiatry 44:9-18.

Cartlidge NEF (1972): Autonomic function in multiple sclerosis. Brain 95:661-664.

Martin DE, Warner H, Crenshaw TL, Crenshaw RT, Shapiro CE, Perkash I (1983): Initiation of erection and semen release by rectal probe electrostimulation (RPE). J Urol 129:639-642.

Ohl DA, Bennett CJ, McCabe M (1988): Predictors of success in electroejaculation. J Urol [Suppl] 139:172A.

Seager SW, Wildt JE, Platz PC (1980): Semen collection by electroejaculation and artificial vagina in over 100 species of animals. Proc 9th Int Conf An Reprod and AI:571.

Thomas RJS, McLeish G, McDonald IA (1975): Electroejaculation of the paraplegic male followed by pregnancy. Med J Aust 2:798-799. 